\title{
Enhanced Optical Nonlinearities in Push-Pull Organic Systems with Polyenic-Mesoionic Ring Mixed Bridges
}

\author{
Ana Elizabete de A. Machado*,\# and Alfredo Arnóbio de S. da Gama \\ Departamento de Química Fundamental, Universidade Federal de Pernambuco, 50740-540 Recife-PE, Brazil
}

\begin{abstract}
Valores elevados da primeira $(\beta)$ e segunda $(\gamma)$ hiperpolarizabilidades foram obtidos para as moléculas apresentando as pontes mistas que contêm os anéis mesoiônicos inseridos entre unidades poliênicas. As magnitudes de $\beta$ e $\gamma$ foram calculadas pela metodologia semi-empírica AM1/TDHF. Pares doador(D)/receptor(A) com diferentes forças foram usados para testar o potencial do novo modelo de ponte. O melhor desempenho foi obtido para o dicianometileno(A) e a fenilamina(D) inseridos nas extremidades opostas das pontes. A fenilamina é ligada ao heteroátomo nitrogênio em contraste com o relatado na literatura em que o sítio de ligação ocorre no anel aromático. $\mathrm{O}$ efeito da natureza e tamanho da ponte na magnitude das hiperpolarizabilidades foi investigado. Os sistemas apresentando as pontes estendidas, contendo dois anéis mesoiônicos, apresentam as maiores magnitudes das hiperpolarizabilidades. Os resultados demonstram que a combinação da ponte selecionada e dos pares D/A podem contribuir para magnitudes muito elevadas das hiperpolarizabilidades $\beta$ e $\gamma$.
\end{abstract}

Large values of the static first $(\beta)$ and $\operatorname{second}(\gamma)$ hyperpolarizabilities were obtained for donoracceptor molecules having mixed bridges with mesoionic rings inserted between polyenic moieties. The magnitudes of $\beta$ and $\gamma$ were calculated at the AM1/TDHF semiempirical level. Donor(D)/ acceptor(A) pairs of different strengths were used to test the potential of the new model bridges. The largest value was obtained by linking the dicyanomethylene(A) and phenylamine(D) at the opposite ends of mixed bridges. Unlike D/A molecules traditionally reported in the literature, the phenylamine was linked to the bridge by the nitrogen heteroatom. The effect of the nature and size of the bridge in the magnitude of the hyperpolarizabilities was investigated. The push-pull systems with the extended bridges, containing two mesoionic rings and polyenic moieties, present the larger magnitudes values of $\beta$ and $\gamma$. The results show that the combination of the selected bridges and D/A pairs can be responsible for very large hyperpolarizabilities.

Keywords: $\beta$ and $\gamma$ hyperpolarizabilities, polyenic/mesoionic bridges, donor-bridge-acceptor organic systems, AM1/TDHF methodology

\section{Introduction}

The possibility of adjusting the structure of organic molecules to maximize the nonlinear optical coefficients has been explored for several classes of compounds. ${ }^{1-8}$ Enhanced values of the second $(\beta)$ and third $(\gamma)$ order polarizabilities were predicted to be found for the appropriate match of structural and electronic properties. While for $\beta$ there is some confidence about the factors that influence its magnitude, for $\gamma$ this level of confidence has not yet been achieved. ${ }^{4,7,8}$ The magnitude of the hyperpolarizabilities can be increased by a broad range of

*e-mail: ana.machado@univasf.edu.br

\#Present address: Universidade Federal do Vale do São Francisco, Colegiado de Engenharia de Produção, 56304-205 Petrolina - PE, Brazil molecular structure and electronic modifications of organic materials. In this way, quantum chemical calculations can be used to test the changes that contribute to optimise the molecular hyperpolarizabilities, and so, to model new compounds for nonlinear optics.

Nonlinear optical materials are considered of importance due to their different applications on optoelectronics. ${ }^{2,3,7}$ Furthermore, new nonlinear media are needed to the implementation of the photonics. Molecular systems containing organic conjugated chains bridging strong donor(D) and acceptor(A) groups are considered to be good candidates to exhibit large molecular hyperpolarizabilities. ${ }^{3,5,7}$ The former characteristic is fundamental to the implementation of some advanced technologies. In addition, other prominent candidates as second-order and third-order nonlinear optical 
materials including chiral molecules, organometallic compounds, octupolar molecules and buckminsterfullerene have attracted the research efforts of theoretical and experimental groups. ${ }^{2-4,7,8}$

Recent AM1/TDHF results for polyenic derivatives showed large values of $\gamma$ when D/A groups are attached at both ends of a polyenic chain. ${ }^{9}$ The best result was obtained by using phenylamine and dicyanomethylene, respectively, as donor and acceptor groups. The link of the donor to the bridge occurs by the $\mathrm{N}$ heteroatom of phenylamine, while traditionally experimental and theoretical groups have used the same donor binding to the bridge by the phenyl moiety. ${ }^{2,7,10,11}$ Large $\beta$ hyperpolarizabilities were theoretically predicted in organic molecules that contain a mesoionic ring as a bridge. ${ }^{11-13}$ More recently, some mesoionic compounds were synthesised, characterized and (AM1/TDHF) theoretically investigated in relation to the $\gamma$ hyperpolarizability. ${ }^{14}$ These molecules display large experimental magnitudes of this nonlinear coefficient. The mesoionic rings present an intrinsic separation of charge. ${ }^{11,15}$ Thus, in order to optimize the $\beta$ and $\gamma$ hyperpolarizabilities, the mesoionic rings were introduced in the polyenic linker of D/A organic molecules. In addition, some D/A pairs of different strengths were tested. The acceptor groups selected for this work were the 1-naphtyl, the nitrophenyl, the cyanomethylene, and the very strong dicyanomethylene group. Phenylamine and phenyl were used as donor groups of electron. The structures of D/A groups are shown in Figure 1. These groups were investigated in push-pull systems reported in the literature by experimental or theoretical groups. ${ }^{2,7,9-12,16-19}$
Donors

$D_{1}$

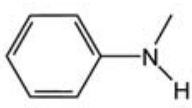

$\mathrm{D}_{2}$

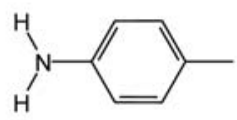

$\mathrm{A}_{3}$

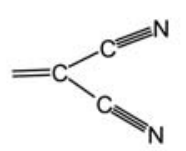

$\mathrm{A}_{4}$

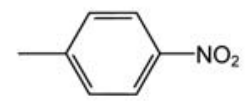

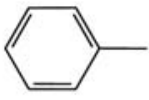

$A_{1}$

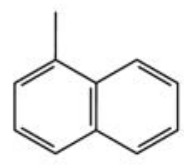

$\mathrm{A}_{2}$

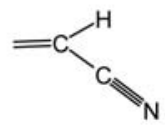

Figure 1. D and A groups investigated in this work.

The effect of linking the phenylamine donor by the phenyl moiety or nitrogen atom on the magnitude of the nonlinear responses $\beta$ and $\gamma$ was studied, considering these two forms. Some systems missing the heteroatom, when the donor group is just phenyl, were also studied. Particularly, the choice of phenylamine as a donor and its binding to the bridge by the nitrogen heteroatom, associate with the dicyanomethylene acceptor, is observed to give the largest amplification on the nonlinear optical coefficients, among the designed systems. This result was already observed on push-pull molecules with pure polyenic bridges at the same level of theory. ${ }^{9,12}$ In this way, it was possible to compare the performance of the mixed bridge donor-acceptor system with those having exclusively polyenic bridges, with similar size and the same D and A groups.

A new model bridge was tested initially with one mesoionic ring inserted between two ethylenic units. Based on the promising results, a second mesoionic ring was introduced separated from the first one by another ethylenic moiety. Indeed, the new model bridges, associated with an efficient D/A pair, promote exceptionally large magnitudes of $\beta$ and $\gamma$. Therefore, the designed systems exhibit interesting properties for potential use as nonlinear optical material.

\section{Method}

The static $\beta$ and $\gamma$ hyperpolarizabilities were calculated by the variational time dependent Hartree-Fock method (TDHF), at the semiempirical AM1 level. ${ }^{20-22}$

Although the experimental hyperpolarizabilities values were not available, for the purpose of comparison with the predicted results, the static values of hyperpolarizabilities in a series of chemically related compounds can be considered by using the same theory. ${ }^{23}$ The calculations were performed using the MOPAC2000 software. ${ }^{24,25}$ The AM1/TDHF methodology was selected because of its good track of reproducing experimental measurements, according with the literature. 9,11,12,14,26

The method was appraised in relation to the first hyperpolarizability $(\beta)$ by considering characterised push-pull organic molecules. ${ }^{11}$ The observed differences between theoretical and experimental $\beta$ values increase when this parameter becomes larger. A larger magnitude of the calculated $\beta$ may be assumed to indicate a relatively larger experimental value.

The AM1/TDHF methodology was also evaluated in relation to the second hyperpolarizability $(\gamma)$ of characterised systems containing one mesoinic ring on the bridge that display large magnitudes of the nonlinear coefficient. ${ }^{14}$ The theoretical results agree with the experimental trends. Also, previous results suggested that model aniline trimers simulate the observed experimental trends for the second hyperpolarizability of polyaniline at the AM1/TDHF level. ${ }^{26}$ 
Furthermore, the evaluation of the $\beta$ and $\gamma$ for characterized organic donor-acceptor systems with exclusively polyenic bridges, using the AM1/TDHF methodology allowed satisfactory analysis..$^{9,12}$ The use of a minimum basis set, the absence of electronic correlation and solvent effects have been recognised to contribute for the observed discrepancies between theoretical and experimental values. ${ }^{3,7}$ Vibrational effects can also be important for this class of material, as observed for some push-pull polyenes. ${ }^{27}$

Therefore, from the arguments presented above, it may be assumed that the semiempirical methodology is a useful instrument to indicate the potential application in nonlinear optics of large organic molecules belonging to a series of chemically related compounds. This approach has the advantage of requiring less computational time, in contrast with $a b$ initio techniques.

\section{Results and Discussion}

The D/A type molecular systems designed for the present investigation are constituted of donor (D) and acceptor (A) groups (Figure 1) attached to the opposite ends of a bridge. For comparison with these selected systems, a molecule with one of the largest reported theoretical static $\beta$ value, labelled as $\mathrm{D}_{2}-\mathrm{B}-\mathrm{A}_{4}$ (Figure 2), was also considered. ${ }^{11}$ Calculations were performed with the same AM1/TDHF semiempirical method. ${ }^{20-22}$ To complete the information about this molecule, the static value of $\gamma$ hyperpolarizability, the ground state dipole moment, and the HOMO-LUMO energy gap were also calculated and are listed in Table 1. A mixed bridge model, $\mathrm{B}_{1}$ (Figure 3), has a structure containing a polyenic chain and a mesoionic ring $\left(R_{M}\right)$. This mesoionic ring is as shown in Figure 2 . The number of polyenic units is varied at both sides of the mesoionic ring, as indicated by the numbers $n_{1}$ and $n_{2}$.

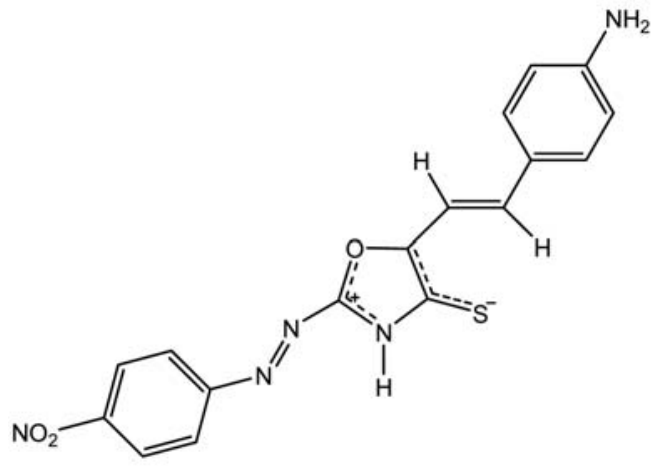

Figure 2. 2(4-nitro-phenyl-azo)-5-(4-amino-phenyl-vinyl)-1,3-oxazolium4-thiolate), labelled as $\mathrm{D}_{2}-\mathrm{B}-\mathrm{A}_{4}$.

The results of static $\beta$ and $\gamma$ for the designed systems containing bridges $\mathrm{B}$ and $\mathrm{B}_{1}$ (Figure 3 ) and the system $\mathrm{D}_{2}-\mathrm{B}-\mathrm{A}_{4}$ are shown in Tables 1 and 2. The results for the systems missing the heteroatom on the donor (phenyl) are presented in Table 2. Also, the ground state dipole moment, the HOMO-LUMO energy gap and the molar mass are presented. The largest hyperpolarizabilities are exhibited by the system $10\left(\mathrm{D}_{1}-\mathrm{B}_{1}-\mathrm{A}_{3}\right)$ constituted of phenylamine $\left(\mathrm{D}_{1}\right)$ as the donor and dicyanomethylene $\left(\mathrm{A}_{3}\right)$ as the acceptor with the bridge $B_{1}\left(n_{1}=n_{2}=2\right)$. This system is planar and shows the smallest energy gap. Therefore, the best performance of this system for the first and second optical

Table 1. Theoretical properties for D-Bridge-A organic molecules

\begin{tabular}{|c|c|c|c|c|c|c|c|c|c|c|}
\hline System & Bridge & $\mathrm{D}$ & A & $\mathrm{n}_{1}$ & $\mathrm{n}_{2}$ & $\beta_{0}$ & $\gamma_{0}$ & $\mu /(D)$ & $\Delta_{\mathrm{H}-\mathrm{L}} /(\mathrm{eV})$ & M \\
\hline 1 & B & $\mathrm{D}_{2}$ & $\mathrm{~A}_{4}$ & & & 405 & 2174 & 3.7 & 4.84 & 367.31 \\
\hline 2 & B & $\mathrm{D}_{1}$ & $\mathrm{~A}_{1}$ & & & 288 & 1330 & 6.2 & 5.00 & 372.44 \\
\hline 3 & B & $\mathrm{D}_{1}$ & $\mathrm{~A}_{2}$ & & & 282 & 563 & 5.8 & 4.95 & 297.33 \\
\hline 4 & B & $\mathrm{D}_{1}$ & $\mathrm{~A}_{3}$ & & & 369 & 188 & 8.6 & 4.79 & 322.34 \\
\hline 5 & $\mathrm{~B}_{1}$ & $\mathrm{D}_{1}$ & $A_{1}$ & 1 & 2 & 228 & 1671 & 7.2 & 5.20 & 396.51 \\
\hline 6 & $\mathrm{~B}_{1}$ & $\mathrm{D}_{1}$ & $\mathrm{~A}_{2}$ & 1 & 2 & 270 & 1227 & 2.9 & 5.10 & 295.36 \\
\hline 7 & $\mathrm{~B}_{1}$ & $\mathrm{D}_{1}$ & $\mathrm{~A}_{3}$ & 1 & 2 & 432 & 1867 & 5.9 & 4.87 & 320.37 \\
\hline 8 & $\mathrm{~B}_{1}$ & $\mathrm{D}_{1}$ & $\mathrm{~A}_{1}$ & 2 & 2 & 257 & 2383 & 7.4 & 5.17 & 422.54 \\
\hline 9 & $\mathrm{~B}_{1}$ & $\mathrm{D}_{1}$ & $\mathrm{~A}_{2}$ & 2 & 2 & 333 & 2119 & 2.7 & 5.05 & 321.40 \\
\hline 10 & $\mathrm{~B}_{1}$ & $\mathrm{D}_{1}$ & $\mathrm{~A}_{3}$ & 2 & 2 & 562 & 3628 & 5.4 & 4.78 & 346.41 \\
\hline 11 & $\mathrm{~B}_{1}$ & $\mathrm{D}_{1}$ & $\mathrm{~A}_{4}$ & 2 & 2 & 421 & 3475 & 1.9 & 4.91 & 417.48 \\
\hline 12 & $\mathrm{~B}_{1}$ & $\mathrm{D}_{2}$ & $\mathrm{~A}_{1}$ & 2 & 2 & 194 & 2183 & 7.9 & 5.24 & 422.54 \\
\hline 13 & $\mathrm{~B}_{1}$ & $\mathrm{D}_{2}$ & $\mathrm{~A}_{2}$ & 2 & 2 & 268 & 1924 & 3.1 & 5.11 & 321.40 \\
\hline 14 & $\mathrm{~B}_{1}$ & $\mathrm{D}_{2}$ & $\mathrm{~A}_{3}$ & 2 & 2 & 445 & 3147 & 5.3 & 4.84 & 346.41 \\
\hline 15 & $\mathrm{~B}_{1}$ & $\mathrm{D}_{2}$ & $\mathrm{~A}_{4}$ & 2 & 2 & 329 & 2990 & 2.1 & 4.99 & 417.48 \\
\hline
\end{tabular}

$\mathrm{B}$ and $\mathrm{B}_{1}$ are the model bridges as shown in Figures 2 and 3 respectively, $\mathrm{n}_{1}$ and $\mathrm{n}_{2}$ are the number of alternated double bonds on the linker at the donor (D) and acceptor (A) side, respectively, D and A groups as shown in Figure 1, static $\beta_{0}\left(10^{-30}\right.$ esu $)$ and $\gamma_{0}\left(10^{-36}\right.$ esu $), \mu$ is the ground state dipole moment in Debye (D), $\Delta_{\mathrm{H}-\mathrm{L}}$ is the HOMO-LUMO energy gap in electron volt (eV), $\mathrm{M}$ is the molar mass. 
Table 2. Investigated $\mathrm{D}_{3}-\mathrm{B}_{1}-\mathrm{A}$ series for study of the case where the $\mathrm{N}$ heteroatom is missing on the donor $\left(\mathrm{n}_{1}=\mathrm{n}_{2}=2\right)$

\begin{tabular}{lcccccccc}
\hline System & Bridge & $\mathrm{D}$ & $\mathrm{A}$ & $\beta_{0}$ & $\gamma_{0}$ & $\mu /(\mathrm{D})$ & $\Delta_{\mathrm{H}-\mathrm{L}} /(\mathrm{eV})$ \\
\hline 16 & $\mathrm{~B}_{1}$ & $\mathrm{D}_{3}$ & $\mathrm{~A}_{1}$ & 135 & 1748 & 9.3 & 5.30 \\
17 & $\mathrm{~B}_{1}$ & $\mathrm{D}_{3}$ & $\mathrm{~A}_{2}$ & 200 & 1426 & 3.9 & 5.18 \\
18 & $\mathrm{~B}_{1}$ & $\mathrm{D}_{3}$ & $\mathrm{~A}_{3}$ & 335 & 2262 & 4.9 & 4.92 \\
\hline
\end{tabular}

$\mathrm{B}_{1}$ is the model bridge (Figure 3), $\mathrm{D}_{3}$ is the phenyl group, A groups as shown in Figure $1, \mathrm{n}_{1}$ and $\mathrm{n}_{2}$ are the number of alternated double bonds on the linker at the donor (D) and acceptor (A) side, respectively, static $\beta_{0}\left(10^{-30} \mathrm{esu}\right)$ and $\gamma_{0}\left(10^{-36} \mathrm{esu}\right), \mu$ is the ground state dipole moment in Debye (D), $\Delta_{\mathrm{H}-\mathrm{L}}$ is the HOMO-LUMO energy gap in electron volt $(\mathrm{eV}), \mathrm{M}$ is the molar mass.

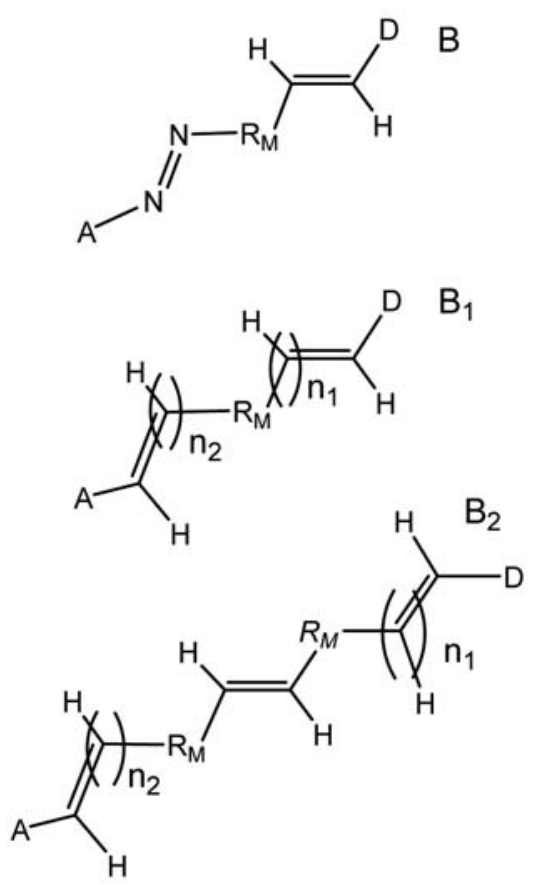

Figure 3. Scheme showing the structures of the B bridge and model mixed bridges $\left(\mathrm{B}_{1}\right.$ and $\left.\mathrm{B}_{2}\right)$ with polyenic moieties and mesoionic ring $\left(\mathrm{R}_{\mathrm{M}}\right)$. The acceptor groups $\mathrm{A}_{2}$ and $\mathrm{A}_{3}$ are directly attached to the double bond at end of the $\mathrm{B}_{1}$ and $\mathrm{B}_{2}$ bridges.

hyperpolarizabilities is in agreement with the simple twolevel and three-level theoretical models.,

Both, HOMO and LUMO of the system 10 have significant contributions of carbon atoms in the ring in a position that connects the linkers bonded to the donor and acceptor, suggesting greater interaction between the bridge and these sites. The sulphur atom in the mesoionic ring contributes to the HOMO, while the oxygen and nitrogen contribute to the LUMO according with the AM1/TDHF calculations.

An important aspect of this system is the binding of the phenylamine donor $\left(D_{1}\right)$ to the bridge through the nitrogen atom. The comparison of the hyperpolarizabilities $\beta$ and $\gamma$ for the systems 10, 14 and 18 respectively with the $\mathrm{D}_{1}, \mathrm{D}_{2}$ and $\mathrm{D}_{3}$ donors (Figure 1), shows that for the same bridge extension and acceptor, $\mathrm{D}_{1}$ is the best donor. The results are shown in Tables 1 and 2. The systems 10 and 14 have the same donor differing by the binding to the bridge through the aromatic ring $\left(\mathrm{D}_{2}\right)$ in the later. Another molecular system was considered, with only a phenyl playing the role of the donor $\left(\mathrm{D}_{3}\right)$, labelled as 18 . This system presents the smallest hyperpolarizabilities. Therefore, the presence of $\mathrm{N}$ heteroatom in the donor linked directly to the $\pi$-system of the bridge leads to higher $\beta$ and $\gamma$ nonlinear responses. Furthermore, a comparison between systems 11 and 15 (Table 1), where the donors are $\mathrm{D}_{1}$ and $\mathrm{D}_{2}$, with the same acceptor $\left(\mathrm{A}_{4}\right)$ and bridge, shows that the best performance is again of the system with $\mathrm{D}_{1}$ as the donor group.

The results for the systems investigated (Tables 1 and 2) suggest that the presence of the phenylamine as the donor $\left(D_{1}\right)$ with the heteroatom linked to the bridge, and the insertion of a mesoionic ring on the polyenic bridge are factors that contribute to increase the $\beta$ and $\gamma$ hyperpolarizabilities.

Taking it further, the effect of introducing a new bridge $\left(\mathrm{B}_{2}\right)$ containing one more mesoionic ring with an ethylenic unit in between was tested, as illustrated in Figure 3. Further increase of the nonlinear coefficients was observed for the system with the efficient pair $\mathrm{D}_{1} / \mathrm{A}_{3}$, labelled as 21 , as shown in Table 3. The mesoionic rings on the bridge is planar, the resonance of the system increases and therefore the hyperpolarizabilities magnitudes is enhanced. The largest values of the $\beta$ and $\gamma$ hyperpolarizabilities are obtained for this system.

Other different strengths of the D/A pairs were used to test the potential of the new model bridge. Hence, the acceptor group 1-naphtyl $\left(\mathrm{A}_{1}\right)$ and the cyanomethylene $\left(\mathrm{A}_{2}\right)$ were selected (Figure 1). The cyanomethylene group is considered to have smaller strength than $\mathrm{A}_{3} .{ }^{9}$ The values of $\beta$ and $\gamma$ (Table 3) are also large but are below that for the system with the dicyanomethylene group. The broad range of $\beta$ and $\gamma$ magnitudes obtained (Tables 1-3) indicate the influence of the nature of the donor, acceptor and bridge, and also the extension of the latter, on the nonlinear responses.

To get insights about the conformational effect, the system $21\left(D_{1}-B_{2}-A_{3}\right)$ was investigated with another conformation, labelled as $21 \mathrm{a}$, in which the second mesoionic ring is inverted in relation for the first ring on the bridge. Moreover, the system $22 \mathrm{a}\left(\mathrm{D}_{2}-\mathrm{B}_{2}-\mathrm{A}_{3}\right)$ was also investigated. 
The results (Table 3) are significant and show the influence of the stereoelectronics on the hyperpolarizability magnitude of this class of nonlinear material. The selected values of the bonds lengths for the systems 10, 21 and 21a are listed in Tables 4 and 5 . The presence of the mesoionic ring in these bridges and the effect of the D/A pair is observed in all polyenic moieties, thus the double bonds $(\mathrm{C}=\mathrm{C})$ lengths are increased while those of single bonds $(\mathrm{C}-\mathrm{C})$ are decreased. In contrast, early theoretical results using $a b$ initio and semiempirical techniques for push-pull polyenic derivatives showed that the effect of D and A groups is stronger in the nearby region of these groups..$^{9,28}$

Furthermore, the calculations of the frequencydependent AM1/TDHF of $\beta$ for the second harmonic generation (SHG) of the systems $10\left(\mathrm{C}_{19} \mathrm{H}_{14} \mathrm{~N}_{4} \mathrm{OS}\right), 21$ and $21 \mathrm{a}\left(\mathrm{C}_{24} \mathrm{H}_{17} \mathrm{~N}_{5} \mathrm{O}_{2} \mathrm{~S}_{2}\right)$ at $0.5 \mathrm{eV}(2480 \mathrm{~nm})$ were performed. Their values are $1139 \times 10^{-30} \mathrm{esu}, 2134 \times 10^{-30} \mathrm{esu}$ and $1465 \times 10^{-30}$ esu, respectively. While the frequencydependent value of $\gamma$ at $0.5 \mathrm{eV}$ relative to the third harmonic generation (THG) for the system 10 is $153719 \times 10^{-36} \mathrm{esu}$. However, the dynamic magnitudes of $\gamma$ for the systems 21 and $21 \mathrm{a}$ at $0.5 \mathrm{eV}$ were not available by the program MOPAC2000 due to numerical problems.

The system $21\left(\mathrm{D}_{1}-\mathrm{B}_{2}-\mathrm{A}_{3}\right)$, that has two mesoionic rings in the bridge and a polyenic moiety between them, presents the best performance relative to both $\beta$ and $\gamma$ among all systems investigated. The conformer $21 \mathrm{a}$ has a large static $\beta$, although its value is smaller than that observed for the system 10 which presents only one ring in the bridge. However, the conformer 21a has a smaller HOMOLUMO energy gap, hence the $\beta(\mathrm{SHG})$ value at $2480 \mathrm{~nm}$ is superior to the dynamic value presented by the system 10 . For the static $\gamma$, the hyperpolarizability magnitude of the system 21a is large and about half of that observed to the conformer 21.

The behaviour of both $\beta$ and $\gamma$ hyperpolarizabilities with the increasing number of ethylenic units in the bridge has been studied for some push-pull systems. ${ }^{9,18,19,28-32}$ Since that the magnitude of optical hyperpolarizabilities grow with the increase of bridge conjugation, the number of polyenic units must be increased beyond the length considered for the investigated systems.

To have insights about the role of isolated mesoionic ring as bridge, calculations were performed in designed donor-acceptor systems where the D/A groups are connected directly to the mesoionic ring. In this particular case, the acceptors $\mathrm{A}_{2}$ and $\mathrm{A}_{3}$, is the cyanoethenyl and the dicyanoethenyl, respectively. The results are presented in Table 6 and are smaller than the obtained for systems containing mixed bridges, but still larger than early results

Table 3. Theoretical properties for organic molecules of $D-B_{2}-A$ type $\left(n_{1}=n_{2}=2\right)$

\begin{tabular}{|c|c|c|c|c|c|c|c|c|}
\hline System & Bridge & $\mathrm{D}$ & A & $\beta_{0}$ & $\gamma_{0}$ & $\mu /(D)$ & $\Delta_{\mathrm{H}-\mathrm{L}} /(\mathrm{eV})$ & M \\
\hline 19 & $\mathrm{~B}_{2}$ & $\mathrm{D}_{1}$ & $\mathrm{~A}_{1}$ & 321 & 4458 & 18.3 & 4.17 & 547.69 \\
\hline 20 & $\mathrm{~B}_{2}$ & $\mathrm{D}_{1}$ & $\mathrm{~A}_{2}$ & 462 & 4982 & 16.6 & 3.99 & 446.54 \\
\hline 21 & $\mathrm{~B}_{2}$ & $\mathrm{D}_{1}$ & $\mathrm{~A}_{3}$ & 723 & 8414 & 13.5 & 3.37 & 471.55 \\
\hline $21 \mathrm{a}$ & $\mathrm{B}_{2}$ & $\mathrm{D}_{1}$ & $\mathrm{~A}_{3}$ & 491 & 4280 & 10.9 & 4.52 & 471.55 \\
\hline $22 \mathrm{a}$ & $\mathrm{B}_{2}$ & $\mathrm{D}_{2}$ & $\mathrm{~A}_{3}$ & 501 & 5890 & 13.8 & 3.75 & 471.55 \\
\hline
\end{tabular}

Donor (D) and acceptor (A) groups as shown in Figure $1, \mathrm{~B}_{2}$ is the model bridge (Figure 3$)$, static $\beta_{0}\left(10^{-30}\right.$ esu) and $\gamma_{0}\left(10^{-36}\right.$ esu), $\mu$ is the ground state dipole moment in Debye (D), $\Delta_{\mathrm{H}-\mathrm{L}}$ is the HOMO-LUMO energy gap in electron volt (eV), $\mathrm{M}$ is the molecular mass, the second mesoionic ring is inverted in relation to the first ring on the bridge for the systems $21 \mathrm{a}$ and $22 \mathrm{a}$.

Table 4. Selected single and double bonds lengths $(\AA)$ for the conjugated chain of the systems $10\left(D_{1}-B_{1}-A_{3}\right), 21$ and $21 \mathrm{a}\left(D_{1}-B_{2}-A_{3}\right)$

\begin{tabular}{lcccccccccccccc}
\hline System & $\mathrm{d}_{1}$ & $\mathrm{~d}_{2}$ & $\mathrm{~d}_{3}$ & $\mathrm{~d}_{4}$ & $\mathrm{~d}_{5}$ & $\mathrm{~d}_{6}$ & $\mathrm{~d}_{7}$ & $\mathrm{~d}_{8}$ & $\mathrm{~d}_{9}$ & $\mathrm{~d}_{10}$ & 1.420 & 1.356 & 1.433 & 1.364 \\
10 & & 1.442 & 1.345 & 1.434 & & & & & 1.421 & 1.353 & 1.437 & 1.361 \\
21 & 1.354 & 1.445 & 1.349 & 1.443 & 1.412 & 1.354 & 1.434 & 1.421 \\
$21 \mathrm{a}$ & 1.355 & 1.441 & 1.351 & 1.433 & 1.413 & 1.357 & 1.411 & 1.434 & 1.357 & 1.426 & 1.370 \\
\hline
\end{tabular}

$\mathrm{d}_{1}-\mathrm{d}_{4}$ are lengths bonds relative to the polyenic moiety near the acceptor group, $\mathrm{d}_{5}-\mathrm{d}_{7}$ are bonds lengths relative to the polyenic moiety between the mesoionic rings, $d_{8}-d_{11}$ are bonds lengths relative to the polyenic moiety near the donor group (see Figure 3 ).

Table 5. Selected bonds lengths $(\AA)$ for the mesoionic rings of the systems $10\left(D_{1}-B_{1}-A_{3}\right), 21$ and $21 a\left(D_{1}-B_{2}-A_{3}\right)$

\begin{tabular}{lllllllllllll}
\hline System & C-O & O-C & C-C & C-N & N-C & C=S & C-O & O-C & C-C & C-N & N-C & C=S \\
\hline 10 & 1.376 & 1.398 & 1.433 & 1.424 & 1.376 & 1.583 & & & & & \\
21 & 1.365 & 1.415 & 1.428 & 1.442 & 1.358 & 1.564 & 1.372 & 1.412 & 1.421 & 1.434 & 1.360 & 1.564 \\
$21 \mathrm{a}$ & 1.374 & 1.398 & 1.435 & 1.422 & 1.367 & 1.581 & 1.367 & 1.424 & 1.420 & 1.443 & 1.359 & 1.581 \\
\hline
\end{tabular}

The first six values are relative for the mesoionic ring near the acceptor group, while the rest is relative for one near the donor group. 
with sydnones derivatives. ${ }^{33}$ Further, large theoretical values of the first hyperpolarizability were obtained for other mesoionic rings structures investigated as bridge in push-pull compounds. ${ }^{34}$

Table 6. Theoretical properties for the $\mathrm{D}-\mathrm{R}_{\mathrm{M}}-\mathrm{A}$ organic molecules

\begin{tabular}{llllll}
\hline System & $\beta_{0}$ & $\gamma_{0}$ & $\mu /(\mathrm{D})$ & $\Delta_{\mathrm{H}-\mathrm{L}} /(\mathrm{eV})$ & $\mathrm{M}$ \\
\hline $\mathrm{D}_{1}-\mathrm{R}_{\mathrm{M}}-\mathrm{A}_{3}$ & 120 & 133 & 5.2 & 5.28 & 268.29 \\
$\mathrm{D}_{1}-\mathrm{R}_{\mathrm{M}}-\mathrm{A}_{2}$ & 76 & 178 & 4.3 & 5.60 & 242.28 \\
$\mathrm{D}_{1}-\mathrm{R}_{\mathrm{M}}-\mathrm{A}_{1}$ & 42 & 152 & 8.0 & 5.78 & 318.39 \\
\hline
\end{tabular}

$\mathrm{D}$ and A groups as shown in Figure 1, $\mathrm{R}_{\mathrm{M}}$ is the mesoionic ring (Figure 2), static $\beta_{0}\left(10^{-30} \mathrm{esu}\right)$ and $\gamma_{0}\left(10^{-36} \mathrm{esu}\right), \mu$ is the ground state dipole moment in Debye (D), $\Delta_{\mathrm{H}-\mathrm{L}}$ is the HOMO-LUMO energy gap in electron volt $(\mathrm{eV}), \mathrm{M}$ is the molar mass.

Optical hyperpolarizability calculations have been performed for polyenic systems with 4, 6 and 8 alternated double bonds in the bridge and the efficient $\mathrm{D}_{1} / \mathrm{A}_{3}$ pair. ${ }^{9,12}$ The AM1/TDHF results for the static $\beta$ and $\gamma$ hyperpolarizabilities are smaller than the obtained for similar mixed bridge length. The polyenic derivative with eight alternated double bonds, for example, has the theoretical values for static $\beta$ and $\gamma, 179 \times 10^{-30}$ esu and $2116 \times 10^{-36}$ esu, respectively.

Recently, a series of D/A systems with mesoionic ring bridges were synthesised and characterised by using Z-scan technique, displaying very high second hyperpolarizabilities. ${ }^{14}$ These molecules have different structures of bridge and D/A pairs compared to the systems investigated in this work, and the AM1/TDHF calculations were performed to obtain the static $\gamma$ values for those molecules. ${ }^{14}$ The results indicate that the system with the best performance presents a magnitude of the static second hyperpolarizability of about $800 \times 10^{-36}$ esu. The values obtained in the present work show that the mixed bridges is an efficient strategy to optimise the $\gamma$ hyperpolarizability.

In 1997, Blanchard-Desce and collaborators synthesized a D/A polyenic derivative containing the strong acceptor 3-(dicyanomethylidenyl)-2,3-dihydrobenzothiophene-2ylidenyl-1,1-dioxide. ${ }^{5}$ This molecule displays one of the highest measured static $\beta$ with a value of $1500 \times 10^{-30} \mathrm{esu}$. The AM1/TDHF magnitude for this molecule is about $200 \times 10^{-30}$ esu. Therefore, the systems selected for the present study may have a larger value of optical hyperpolarizabilities (see Tables 1,2 and 3), particularly the system 21 with the static $\beta$ of $723 \times 10^{-30}$ esu, since that the experimental hyperpolarizabilities values are observed to be larger than the semiempirical theoretical prediction. ${ }^{7,9,11,12,26}$ Furthermore, the static AM1/TDHF theoretical values of $\beta$ and $\gamma$ are relative to vacuum and are expected to increase in the presence of a solvent. ${ }^{14,26,27,35,36}$ Hence, the theoretical values obtained in this work may be amplified in the presence of a solvent.

The performance of the second hyperpolarizability for all systems investigated in this work is good, showing values of $\gamma$ that are superior to the natural carotene. By using the same (AM1/TDHF) theory, the static $\gamma$ for this molecule was calculated and has the value of $1696 \times 10^{-36}$ esu. Although carotenoids and long polyenic derivatives show nonlinear responses that are among the highest reported in the literature, problems of instability relative to exposure to air and light, prevent currently the manufacture of devices. ${ }^{8,27}$ By the way, the mesoionic compounds are stable, with relative high melting point and can be obtained in crystalline form. ${ }^{11,37}$ Therefore, the use of mixed bridges contained one or more mesoionic rings inserted in polyenic units, may open a new perspective of practical application for the organic molecules as nonlinear optical materials.

\section{Conclusions}

The analysis of a series of designed push-pull molecules indicates that a structure of bridge containing polyenic moieities and mesoionic rings is efficient to enhance of both $\beta$ and $\gamma$ hyperpolarizabilities, as shown by comparing the results to those of similar D/A compounds containing exclusively polyenic bridges. ${ }^{9,12}$ The strength of a selected donor-acceptor pair is also important for the increasing of the nonlinear coefficients as observed in the series investigated. Particularly, the way a donor is bonded to the conjugated bridge, may influence its effect, as demonstrated when the phenylamine is linked through the nitrogen heteroatom.

It was also noted a strong conformational effect on the magnitudes of the first and second hyperpolarizabilities, particularly for the systems 21 and 21a. Therefore, it can be a way in the direction of optimizing the nonlinear coefficients for this class of material.

More rigorous calculations, including electronic correlation and solvent effects, are recommended for the more promising investigated molecules, considering the contribution for a better understanding of the nonlinearity mechanism in these systems, particularly the role of the phenylamine heteroatom.

The synthesis of the designed systems for performing $\beta$ and $\gamma$ measurements will be fundamental to complete this investigation. The large magnitudes obtained at the AM1/ TDHF level indicate that the designed molecules show potential applications for optoelectronic and photonic. Further increase of the $\beta$ and $\gamma$ parameters may be obtained by extending the bridges with more polyenic or mesoionic units, as well as to test other structures of mesoionic rings. 
From these results, the AM1/TDHF semiempirical methodology may be assumed to be helpful for modelling, and consequently for selecting large organic molecules with potentially enhanced nonlinear responses.

\section{Acknowledgments}

The authors acknowledge the financial support from Conselho Nacional de Desenvolvimento Científico e Tecnológico (MCT/CNPq) and Fundação de Amparo à Ciência e a Tecnologia do Estado de Pernambuco (FACEPE).

\section{References}

1. Marder, S. R.; Sohn, J. E.; Stucky, G. D., eds.; Materials for Nonlinear Optics: Chemical Perspectives, ACS Symp. Ser. 455, American Chemical Society: Washington, 1991.

2. Zyss, J.; Molecular Nonlinear Optics: Materials, Physics and Devices, Academic Press: Boston, 1994.

3. Brédas, J. L.; Adant, C.; Tackx, P.; Persoons, A.; Pierce, B. M.; Chem. Rev. 1994, 94, 243.

4. Tykwinski, R. R.; Gubler, U.; Martin, R. E.; Diederich, F.; Bosshard, C.; Günter, P.; J. Phys. Chem. B 1998, 102, 4451.

5. Blanchard-Desce, M.; Alain, V.; Bedworth, P. V.; Marder, S. R.; Fort, A.; Runser, C.; Barzoukas, M.; Lebus, S.; Wortmann, R.; Chem. Eur. J. 1997, 3, 1091.

6. Risser, S. M.; Beratan, D. N.; Marder, S. R.; J. Am. Chem. Soc. 1993, 115, 7719.

7. Kanis, D. R.; Ratner, M. A.; Marks, T. J.; Chem. Rev. 1994, 94, 195.

8. Marder, S. R.; Torruellas, W. E.; Blanchard-Desce, M.; Ricci, V.; Stegeman, G. I.; Gilmour, S.; Brédas, J.-L.; Li, J.; Bublitz, G. U.; Boxer, S. G.; Science 1997, 276, 1233.

9. Machado, A. E. de A.; Gama, A. A. S da; THEOCHEM 2003, 620, 21.

10. Kanis, D. R.; Marks, T. J.; Ratner, M. A.; Int. J. Quantum Chem. 1992, 43, 61

11. Moura, G. L. C.; Simas, A. M.; Miller, J.; Chem. Phys. Lett. 1996, 257, 639.

12. Machado, A. E. de A.; PhD Thesis, Universidade Federal de Pernambuco, Brazil, 2001.

13. Machado, A. E. de A.; Neto, B. B.; Gama, A. A. S. da; J. Comput. Meth. Sci. Eng. 2004, 4, 267.

14. Bezerra, A. G.; Gomes, A. S. L.; Athayde-Filho, P. F.; Rocha, G. B. da; Miller, J.; Simas, A. M.; Chem. Phys. Lett. 1999, 309, 421.
15. Fabian, J.; Hess Jr, B. A.; Int. J. Quantum Chem. 2002, 90, 1055.

16. Hermant, R. M.; Bakker, N. A. C.; Scherer, T.; Krijnen, B.; Verhoeven, J. W.; J. Am. Chem. Soc. 1989, 111, 4433.

17. Slama-Schwok, A.; Blanchard-Desce, M.; Lehn, J.-M.; J. Phys. Chem. 1990, 94, 3894.

18. Matsuzawa, N.; Dixon, D. A.; Int. J. Quantum Chem. 1992, 44, 497.

19. Champagne, B.; Kirtman, B.; Chem. Phys. 1999, 245, 213.

20. Kurtz, H. A.; Stewart, J. J. P.; Dieter, K. M.; J. Comput. Chem. 1990, 11, 82.

21. Karna, S. P.; Dupuis, M.; J. Comput. Chem. 1991, 12, 487.

22. Dewar, M. J. S.; Zoebisch, E. G.; Healy, E. F.; Stewart, J. J. P.; J. Am. Chem. Soc. 1985, 107, 3902.

23. Willetts, A.; Rice, J. E.; Burland, D. P.; Shelton, D.M.; J. Chem. Phys. 1992, 97, 7590.

24. Stewart, J. J. P.; J. Comput.-Aided Mol. Des. 1990, 4, 1.

25. Stewart, J. J. P.; MOPAC2000 Manual, Fujitsu Limited: Tokyo, Japan, 1999.

26. Machado, A. E. de A.; Petrov, D. V.; Falcão, E. H. L.; Gama, A. A. S. da; Azevêdo, W. M. de; Chem. Phys. Lett. 2002, 356, 451.

27. Champagne, B.; Kirtman, B. In Handbook of Advanced Electronic and Photonic Materials and Devices, Nalwa, H. S., ed.; Vol. 9, Academic: San Diego, 2001, ch. 2.

28. Meyers, F.; Brédas, J.-L.; Zyss, J.; J. Am. Chem. Soc. 1992, 114, 2914.

29. Blanchard-Desce, M.; Lehn, J.-M.; Barzoukas, M.; Runser, C.; Fort, A.; Puccetti, G.; Ledoux, I.; Zyss, J.; Nonlinear Opt. 1995, $10,23$.

30. Puccetti, G.; Blanchard-Desce, M.; Ledoux, I.; Lehn, J.-M.; Zyss, J.; J. Phys. Chem. 1993, 97, 9385.

31. Blanchard-Desce, M.; Wortmann, R.; Lebus, S.; Lehn, J.-M.; Krämer, P.; Chem. Phys. Lett. 1995, 243, 526.

32. Barzoukas, M.; Blanchard-Desce, M.; Josse, D.; Lehn, J.-M.; Zyss, J.; Chem. Phys. 1989, 133, 323.

33. Morley, J. O.; J. Phys. Chem. 1995, 99, 1923.

34. Silva, A. M. S.; Rocha, G. B.; Meneses, P. H.; Miller, J.; Simas, A. M.; J. Braz. Chem. Soc. 2005, 16, 583.

35. Champagne, B.; Mennucci, B.; Cossi, M.; Cammi, R.; Tomasi, J.; Chem. Phys. 1998, 238, 153.

36. Machado, A. E. de A.; Gama, A. A. S. da; Int. J. Quantum Chem. 2005, 103, 625.

37. Echeverria, A.; Miller, J.; J. Chem. Res. (S) 1987, 391.

Received: June 22, 2007 Web Release Date: August 28, 2008 